\title{
Synthesis of Polysilsesquioxanes with Double-Decker Silsesquioxane Repeating Units
}

\author{
M. A. Hoque ${ }^{1 *}$, Y. Kawakami \\ ${ }^{1}$ Department of Materials Science \& Engineering, University of Rajshahi, Rajshahi-6205, \\ Bangladesh \\ ${ }^{2}$ Professor Emeritus, Japan Advanced Institute of Science and Technology, Nomi, \\ Ishikawa 923-1292 Japan
}

Received 22 February 2016, accepted in final revised form 23 March 2016

\begin{abstract}
Polysilsesquioxanes were synthesized with end functional double-decker silsesquioxanes (DDSQ) and the polymers were characterized with ${ }^{1} \mathrm{H}$ NMR, ${ }^{29} \mathrm{Si}$ NMR and size exclusion chromatography (SEC). Polysilsesquioxane containing iso-butyl end capped DDSQ showed better solubility compared to that of methyl end capped DDSQ. Thermal properties investigated with TGA showed that the polymers exhibited exceptionally high stabilities in the range of $470-530^{\circ} \mathrm{C}$ even in both nitrogen and air atmosphere. The average residual weights of the polymers at $760^{\circ} \mathrm{C}$ were around $80 \%$ in the nitrogen atmosphere.
\end{abstract}

Keywords: Polysilsesquioxane; Double-decker silsesquioxane; Cross-dehydrocoupling reaction; Thermally stable polymer; Polycondensation.

(C)2016 JSR Publications. ISSN: 2070-0237 (Print); 2070-0245 (Online). All rights reserved.

doi: http://dx.doi.org/10.3329/jsr.v8i2.26791 J. Sci. Res. 8 (2), 217-227 (2016)

\section{Introduction}

Linear polysiloxanes have been well-known to show particular characteristics such as flexibility of the main chain, low glass transition temperature, thermo-stability, stability against oxidation, and physiological inertness [1-2]. This polysiloxane is also a kind of good candidates as high-temperature elastomer because of the property originated from flexible and heat-resistant $\mathrm{Si}-\mathrm{O}-\mathrm{Si}$ backbone [3-6]. For the expanded and high temperature application of polysiloxane, glass transition temperature $T_{\mathrm{g}}$ and thermal stability must be improved.

Introduction of bulky and rigid moieties like phenylene, naphthylene, anthrylene, phenanthrylene and adamantyl moieties in main chain exhibits high $T_{\mathrm{g}}$ and good thermal

* Corresponding author: $\underline{\text { hoque mse@ru.ac.bd }}$ 
stabilities of the polysiloxanes [7-11]. However, this introduction of organic moieties breaks the continuity of Si-O-Si backbone in the chemical structure of the formed polymer.

There are few attempts to improve the physical properties by the introduction of polyhedral oligomeric silsesquioxane (POSS) unit in main chain of polysiloxane in place of the bulky and rigid organic moieties [12-14]. Moreover, incorporation of POSS unit in backbone of the linear step-condensed polymer in definite structure was quite difficult as the polycondensation of POSS having multiple reactive sites of equivalent reactivity with di-functional monomers typically generates insoluble cross-linked products [15-18]. The problems caused by the multi-functionality of POSS could be readily eradicated by replacing POSS with double-decker silsesquioxane (DDSQ) having two definite polymerizable functional groups. Recently some researchers synthesized polysilsesquioxane having DDSQ units in the main chain [19-20]. They used bi-functional DDSQ unit having organic spacers. In those cases, they obtained high molecular weight polymers having alternative silsesquioxane unit and organic unit giving -Si-O-Si-Cbackbone. Hoque et al. [21] introduced DDSQ units as bulky and rigid moiety groups instead of organic moieties in the backbone to produce the copolymers with linear tetrasiloxane retaining continuous $\mathrm{Si}-\mathrm{O}-\mathrm{Si}$ backbone. This polymer consists of DDSQ and linear Si-O-Si linker showed significant improvement in thermal stability.

If a polymer was synthesized with only DDSQ units without any single chain siloxane linker which is susceptible to acid or basic medium [1-2] would further increase the mechanical dimension, thermal stability and resistivity to acidic or basic medium of the polymer. So far the knowledge of the author, no any author has reported polysilsesquioxane having only DDSQ unit in the main chain.

In this study, we preliminarily report the synthesis of a new polymer consisting of only bi-functional DDSQ's as monomers. Formation of polymeric backbone was examined with proton and silicon NMR. The effect of cage type building block (DDSQ) on thermal property was investigated.

\section{Experimental}

\subsection{Materials}

Phenyltrimethoxysilane, methyldichlorosilane, methyltrichlorosilane, and isobutyltrichlorosilane were purchased from Shin-Etsu Chemicals, Japan, Tris(pentafluorophenyl)borane, $\mathrm{B}\left(\mathrm{C}_{6} \mathrm{~F}_{5}\right)_{3}(95 \%$ purity), sodium hydroxide and sodium sulfate were purchased from Sigma Aldrich. Triethylamine (TEA) was purchased from Wako Pure Chemical Industries Ltd., Japan. All these chemicals were used as received. Tetrahydrofurn, toluene, chloroform, hexane, methanol and $i$-propanol were used after drying by distillation. 


\subsection{Instrumental analysis}

${ }^{1} \mathrm{H}(300 \mathrm{MHz})$ and ${ }^{29} \mathrm{Si}(99.5 \mathrm{MHz}) \mathrm{NMR}$ spectra were obtained on Varian Gemini 2000 and Unity Inova in $\mathrm{CDCl}_{3}$ respectively. Chemical shifts are given in ppm relative to internal $\mathrm{CHCl}_{3}$ (7.26) for ${ }^{1} \mathrm{H}$ and tetramethylsilane (0.00) for ${ }^{29} \mathrm{Si}$. For MALDI-TOF MS (Voyager-DE RP) analysis, the matrix 2,5-dihydroxybenzoic acid was dissolved in THF $(10 \mathrm{mg} / \mathrm{ml})$, and $0.2 \mu \mathrm{L}$ of sample solution (100 $\mu \mathrm{mol}$ in THF) was mixed with matrix $(1: 1 \mathrm{v} / \mathrm{v}$ ratio). The resultant solution was deposited on a stainless steel sample plate and dried. The measurement was done in linear mode with UV laser $(337 \mathrm{~nm})$, and positive mode with an accelerating voltage of $20 \mathrm{kV}$. The spectra were calibrated by using the sample of angiotensin I with the matrix of $\alpha$-cyano-4-hydroxycinnamic acid. All the data was collected by laser intensity $1901(3.0 \mathrm{~Hz})$ with accumulation of laser shots 50/spectra. Size exclusion chromatography (SEC) was performed on a JASCO high speed liquid chromatograph, model Gulliver 900 with combination of Shodex KF-801 (exclusion limit: polystyrene $1.5 \times 10^{3} \mathrm{Da}$ ) and $\mathrm{KF}-802$ (exclusion limit: polystyrene $5 \times 10^{3} \mathrm{Da}$ ) for monomers and Shodex KF-804 (exclusion limit: polystyrene $4 \times 10^{5} \mathrm{Da}$ ) and KF-805 (exclusion limit: polystyrene $4 \times 10^{6} \mathrm{Da}$ ) for polymers using THF as eluent. The thermal stabilities of polymers were investigated by SEIKO SSC/5200H TGA under nitrogen at a heating rate of $10{ }^{\circ} \mathrm{C} / \mathrm{min}$. Fourier transform infrared (FT-IR) spectra were obtained with $\mathrm{KBr}$ disc on a JASCO VALOR-III (resolution of $4 \mathrm{~cm}^{-1}, 400-4000 \mathrm{~cm}^{-1}$ ) at room temperature.

\subsection{Synthesis of precursor and monomers}

Tetrasodium salt of double-decker silsesquioxane precursor DDSQ(ONa) [22]

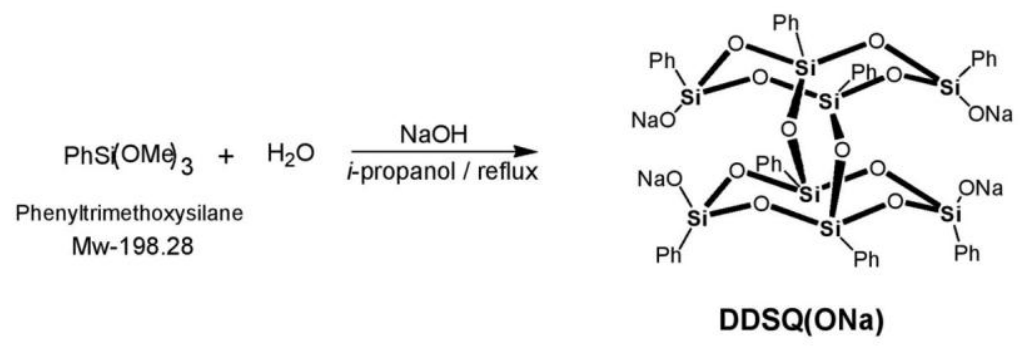

$\mathrm{PhS}(\mathrm{OMe})_{3}+\mathrm{H}_{2} \mathrm{O} \underset{i \text {-propanol / reflux }}{\longrightarrow}$

$\mathrm{Mw}-198.28$

Apparent Mw : 1157 by SEC

Scheme 1. Synthesis of a double-decker silsesquioxane DDSQ(ONa).

Phenyltrimethoxysilane (48 g, $0.24 \mathrm{~mol}$ ) was added drop-wise to a solution of sodium hydroxide $(6.4 \mathrm{~g}, 0.16 \mathrm{~mol})$ in $i$-propanol $(240 \mathrm{~mL})$ and deionized water $(5 \mathrm{~g}, 0.28 \mathrm{~mol})$ at room temperature for about $15 \mathrm{~min}$. The reaction mixture was heated to reflux for $4 \mathrm{hrs}$ under nitrogen. The solution was cooled to ambient temperature, and left standing for 
about $15 \mathrm{~h}$. After filtration, the precipitate was washed with $i$-propanol and dried at $70{ }^{\circ} \mathrm{C}$ for $5 \mathrm{~h}$ in a vacuum oven to obtain $23.9 \mathrm{~g}$ of colorless powder of DDSQ(ONa), $68.2 \%$ yield. IR (KBr): 1430, $1600(\mathrm{Si}-\mathrm{Ph}) \mathrm{cm}^{-1}, 1200 \sim 950(\mathrm{Si}-\mathrm{O}-\mathrm{Si}) \mathrm{cm}^{-1}$; One peak in SEC.

Synthesis scheme of double-decker monomers are shown in Scheme 2.

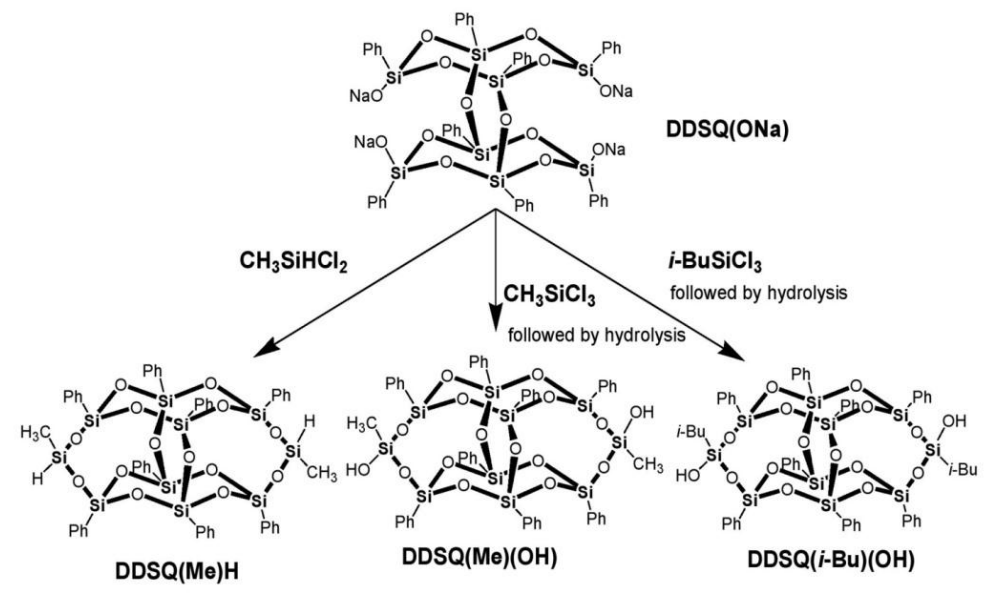

Scheme 2. Synthesis of DDSQ(Me)H, DDSQD(Me)(OH) and DDSQ $(i-\mathrm{Bu})$ monomers.

\section{$\operatorname{DDSQ}(\mathrm{Me}) \mathrm{H}[23]$}

DDSQ(ONa) (11.6 g, $10.0 \mathrm{mmol})$ was vacuum dried at elevated temperature in a $300 \mathrm{~mL}$ round bottom two neck flask. Triethylamine $(30 \mathrm{~mL}, 3.0 \mathrm{~g})$ and THF $(100 \mathrm{~mL})$ were then added to DDSQ $(\mathrm{ONa})$ under nitrogen. To the flask, methyldichlorosilane (30 mmol, $3.4 \mathrm{~g}$ ) was added dropwise and the mixture was stirred at room temperature for $2 \mathrm{hrs}$. The formed salts $\left(\mathrm{NaCl}\right.$ and $\left.\mathrm{Et}_{3} \mathrm{NHCl}\right)$ were removed by filtration. The solution was then subjected to rotary evaporation to remove the unreacted methyldichlorosilane, solvent and $\mathrm{Et}_{3} \mathrm{~N}$. Drying was commenced to find white residue which was re-dissolved in THF and re-precipitated in $400 \mathrm{~mL}$ toluene. Re-precipitation was done twice, and the product was dried in vacuum for $8 \mathrm{hrs} .{ }^{1} \mathrm{H}$ NMR $\left(300 \mathrm{MHz}, \mathrm{CDCl}_{3}\right): \delta(\mathrm{ppm}) 0.37\left(\mathrm{~d}, 6 \mathrm{H}, \mathrm{SiCH}_{3}\right), 4.98$ (q, 2H, SiH), 7.18-7.56 (m, 40H, Ph); $\left.{ }^{29} \mathrm{Si} \mathrm{NMR} \mathrm{(99.5} \mathrm{MHz,} \mathrm{CDCl}_{3}\right): \delta(\mathrm{ppm})-79.32(\mathrm{t}$, 4Si), -77.83 (s, 4Si), -32.77 (s, 2Si); MALDI-TOF (m/z): $1175.95\left(\mathrm{M}^{+}+\mathrm{Na}^{+}\right)$, calc: 1175.06; One peak in SEC.

\section{$\operatorname{DDSQ}(\mathrm{Me})(\mathrm{OH})[23]$}

A $300 \mathrm{~mL}$ three neck flask equipped with a dropping funnel, a reflux condenser and a thermometer was charged with the compound DDSQ(ONa) (11.6 gm, $10 \mathrm{mmol})$, THF $(100 \mathrm{gm})$ and triethylamine $(3.0 \mathrm{~g}, 30 \mathrm{mmol})$, and it was sealed with dry nitrogen. 
Methyltrichlorosilane $(4.5 \mathrm{~g}, 30 \mathrm{mmol})$ was added drop-wise thereto at room temperature while stirring by means of a magnetic stirrer. Then, the solution was stirred at room temperature for $3 \mathrm{~h}$. Water $(50 \mathrm{~g})$ was added to the reaction mixture and stirred for $30 \mathrm{~min}$ to dissolve sodium chloride formed and to hydrolyze un-reacted methyltrichlorosilane. The reaction mixture thus obtained was subjected to extraction with toluene $(150 \mathrm{~mL})$, and the organic layer was washed once with $1 \mathrm{~N} \mathrm{HCl}$ acid and once again with the saturated solution of sodium hydrogen carbonate. It was further washed repeatedly three times with ion-exchanged water. The organic layer obtained was dried on anhydrous magnesium sulfate, filtrate and then solvent was removed under reduced pressure by the rotary evaporator to obtain $7.1 \mathrm{gm}$ of white powdery solid. ${ }^{1} \mathrm{H} \mathrm{NMR}\left(300 \mathrm{MHz}, \mathrm{CDCl}_{3}\right)$ : $\delta$ (ppm) 0.36 (s, 6H, $\left.\mathrm{SiCH}_{3}\right), 2.66$ (s, 2H, SiOH), 7.17-7.57 (m, 40H, Ph); ${ }^{29} \mathrm{Si} \mathrm{NMR} \mathrm{(99.5}$ $\left.\mathrm{MHz}, \mathrm{CDCl}_{3}\right): \delta(\mathrm{ppm})-79.17(\mathrm{t}, 4 \mathrm{Si}),-78.61(\mathrm{~s}, 4 \mathrm{Si}),-53.91(\mathrm{~s}, 2 \mathrm{Si})$; MALDI-TOF $(\mathrm{m} / \mathrm{z})$ : $1207.22\left(\mathrm{M}^{+}+\mathrm{Na}^{+}\right)$calc: 1207.05; One peak in SEC; FT-IR: 3450, 3070, 2971, $1594,1430,1270,1088,909,730 \mathrm{~cm}^{-1}$.

\section{$\operatorname{DDSQ}(\mathrm{i}-\mathrm{Bu})(\mathrm{OH})[21]$}

To a $100 \mathrm{~mL}$ two neck flask equipped with a reflux condenser, DDSQ(ONa) (3 g, 2.59 $\mathrm{mmol})$, THF $(30 \mathrm{~mL})$ and triethylamine $(0.78 \mathrm{~g}, 7.78 \mathrm{mmol})$ were placed and sealed with dry nitrogen. Isobutyltrichlorosilane $\left(i-\mathrm{BuSiCl}_{3}, 1.5 \mathrm{~g}, 7.78 \mathrm{mmol}\right)$ was added drop-wise thereto with a syringe at room temperature while stirring by means of a magnetic stirrer. Then, the solution was stirred at a room temperature for $12 \mathrm{~h}$. Water $(13 \mathrm{~mL})$ was added to the reaction mixture and stirred for $20 \mathrm{~min}$ to dissolve sodium chloride formed and hydrolyzed unreacted isobutyltrichlorosilane. The reaction mixture thus obtained was subjected to extraction with toluene $(50 \mathrm{~mL})$, and the organic layer was washed repeatedly with ion-exchanged water until it became neutral. The organic layer obtained was dried on anhydrous sodium sulfate and the volume of toluene was reduced to form precipitate of less soluble by-products. The toluene solution containing precipitated by-product was put at $0^{\circ} \mathrm{C}$ for overnight and then filtered to remove the formed precipitates. Hexane was added drop-wise to the filtrate obtained to induce new precipitation, which was again put at $0^{\circ} \mathrm{C}$ for overnight. The solid product formed was filtered and collected, and dried to obtain $1 \mathrm{gm}$ of a white solid. ${ }^{1} \mathrm{H}$ NMR $\left(300 \mathrm{MHz}, \mathrm{CDCl}_{3}\right): \delta$ (ppm) 0.80, 0.81 (two d, $\mathrm{SiCH}_{2}$ ), 0.90, 0.91 (two d, 12H, $\mathrm{CH}_{3}$ ), 1.81-2.00 (m, 4H, CH), 2.59 (s, 2H, SiOH), 7.197.57 (m, 80 H, Ph); ${ }^{29} \mathrm{Si} \mathrm{NMR} \mathrm{(99.5} \mathrm{MHz,} \mathrm{CDCl}_{3}$ ): $\delta$ (ppm) -79.32, -79.28, -79.19, -78.90, -55.95; MALDI-TOF (m/z): $1292.35\left(\mathrm{M}^{+}+\mathrm{Na}^{+}\right)$, calc. 1291.16; One peak in SEC.

\subsection{Synthesis of polymers}

Polymer P1 and P2 were synthesized by the cross-dehydrocoupling polymerization as shown in Scheme 3. To a $10 \mathrm{~mL}$ of one-neck round bottom flask, DDSQ(Me)H $(0.2 \mathrm{~g}$, $0.173 \mathrm{mmol})$, DDSQ(Me)(OH) $(0.21 \mathrm{~g}, 0.173 \mathrm{mmol})$ and $\mathrm{B}\left(\mathrm{C}_{6} \mathrm{~F}_{5}\right)_{3}(0.0035 \mathrm{~g}, 2 \mathrm{~mol} \%)$ were placed for the synthesis of P1 and, DDSQ(Me)H (0.18 g, $0.16 \mathrm{mmol})$, DDSQ(i- 
$\mathrm{Bu})(\mathrm{OH})(0.2 \mathrm{~g}, 0.16 \mathrm{mmol})$ and $\mathrm{B}\left(\mathrm{C}_{6} \mathrm{~F}_{5}\right)_{3}(0.0035 \mathrm{~g}, 2 \mathrm{~mol} \%)$ were placed for the synthesis of P2. After drying, the flask was sealed with argon atmosphere and $1 \mathrm{~mL}$ of toluene (dried with sodium metal) was added at $70{ }^{\circ} \mathrm{C}$ and reaction mixture was stirred at $90{ }^{\circ} \mathrm{C}$. After few minutes of stirring, the DDSQ monomers went to the solution with hydrogen bubbling, which confirmed the progress of reaction. The reacting solution was further stirred for 12 hours and then the mixture was poured into methanol to give the precipitation which was dried in vacuum to get $0.28 \mathrm{~g}$ (68\% yield) and $0.29 \mathrm{~g}$ (72\% yield) of the polymer P1 and P2, respectively. The crude polymers were purified by repeated reprecipitation from THF into methanol.

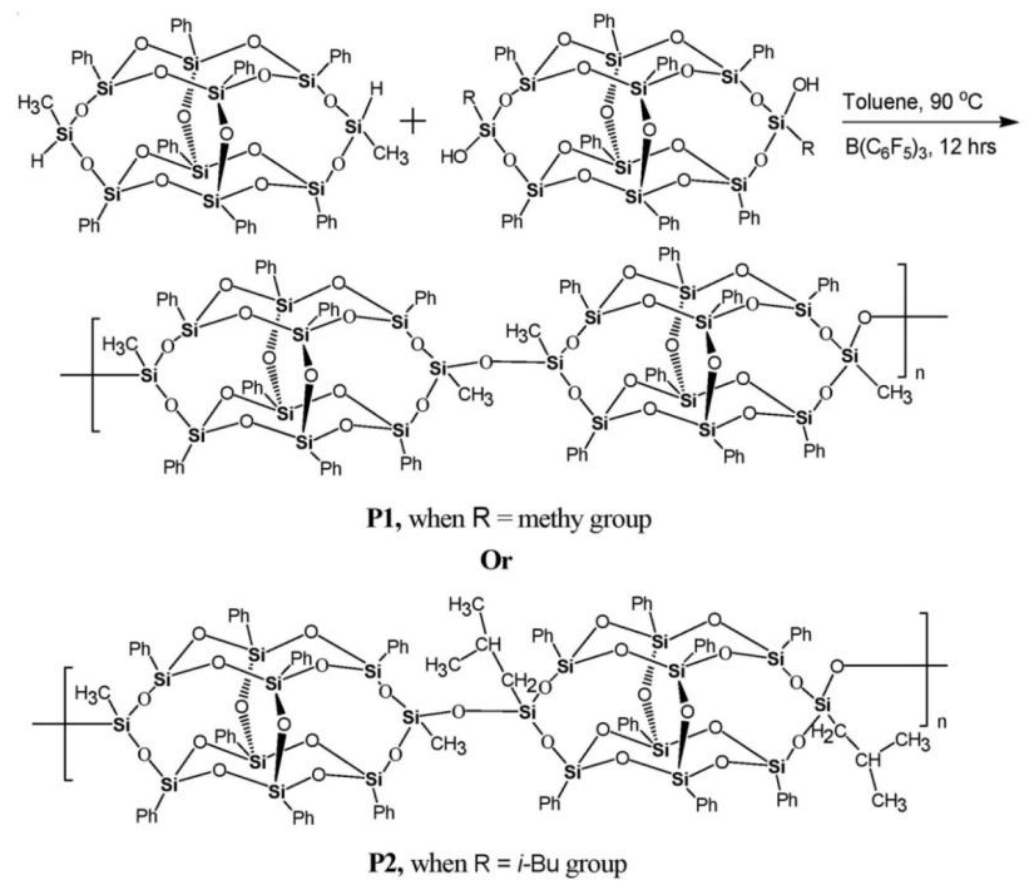

Scheme 3. Cross-dehydrocoupling polymerization of DDSQ(Me)H and DDSQ(Me)(OH) for the synthesis of polymer P1, DDSQ(Me)H and DDSQ $(i-\mathrm{Bu})(\mathrm{OH})$ for the synthesis of polymer P2 using $\mathrm{B}\left(\mathrm{C}_{6} \mathrm{~F}_{5}\right)_{3}$ as catalyst.

For Polymer P1: ${ }^{1} \mathrm{H}$ NMR (300 MHz, $\mathrm{CDCl}_{3}$ ): $\delta(\mathrm{ppm}) 0.21$ (s, 6H, $\mathrm{CH}_{3}$ ), 6.91-7.50 $(\mathrm{m}, 40 \mathrm{H}, \mathrm{Ph}) ;{ }^{29} \mathrm{Si} \mathrm{NMR}\left(99.5 \mathrm{MHz}, \mathrm{CDCl}_{3}\right): \delta(\mathrm{ppm})-79.50(\mathrm{t}, 4 \mathrm{Si}),-79.00$ (s, 4Si), 64.44 (s, 2Si); GPC: $M_{\mathrm{n}}=9000, M_{\mathrm{w}}=23000, M_{\mathrm{w}} / M_{\mathrm{n}}=2.55$. For Polymer P2: ${ }^{1} \mathrm{H}$ NMR $\left(300 \mathrm{MHz}, \mathrm{CDCl}_{3}\right): \delta(\mathrm{ppm}) 0.08\left(\mathrm{~s}, 6 \mathrm{H}, \mathrm{CH}_{3}\right), 0.22\left(4 \mathrm{H}\right.$, isobutyl- $\left.\mathrm{CH}_{2}\right), 0.63(12 \mathrm{H}$, isobutyl- $\left.\mathrm{CH}_{3}\right), 1.75\left(2 \mathrm{H}\right.$, isobutyl-CH), 6.90-7.44 (m, 80H, Ph); ${ }^{29} \mathrm{Si} \mathrm{NMR}(99.5 \mathrm{MHz}$, $\left.\mathrm{CDCl}_{3}\right): \delta(\mathrm{ppm})-79.80$ to $-79.20(\mathrm{~m}),-79.04(\mathrm{~s}),-66.73(\mathrm{~s}),-64.97(\mathrm{~s}) ; \mathrm{GPC}: M_{\mathrm{n}}=9000$, $M_{\mathrm{w}}=24000, M_{\mathrm{w}} / M_{\mathrm{n}}=2.66$. 


\section{Results and Discussion}

\subsection{Synthesis of polymers}

Several attempts were made to synthesize polymers from DDSQ(Me)(OH) and DDSQ $(i$ $\mathrm{Bu})(\mathrm{H})$, and $\mathrm{DDSQ}(i-\mathrm{Bu})(\mathrm{OH})$ and $\operatorname{DDSQ}(i-\mathrm{Bu}) \mathrm{H}$ as monomers, prior to the synthesis of $\mathrm{P} 1$ from DDSQ(Me)H and DDSQ(Me)(OH) and P2 from DDSQ(Me)H and DDSQ $(i-$ $\mathrm{Bu})(\mathrm{OH})$. No reaction proceeded at $100^{\circ} \mathrm{C}$ for even $72 \mathrm{hrs}$ reaction time in toluene with $\mathrm{B}\left(\mathrm{C}_{6} \mathrm{~F}_{5}\right)_{3}$ as catalyst.

Table 1. Polymerization of DDSQ monomers with feed ratio $1: 1$, catalyzed by $\mathrm{B}\left(\mathrm{C}_{6} \mathrm{~F}_{5}\right)_{3}(2$ mol\%).

\begin{tabular}{|c|c|c|c|c|c|}
\hline \multirow{3}{*}{ Run } & \multicolumn{2}{|c|}{ DDSQ monomers in toluene } & \multicolumn{2}{|c|}{ Reaction bath } & \multirow{3}{*}{ Results } \\
\hline & M1 & M2 & \multirow[t]{2}{*}{ Time (h) } & \multirow[t]{2}{*}{ Temp, $\left({ }^{\circ} \mathrm{C}\right)$} & \\
\hline & Molar ratio $(1: 1)$ & & & & \\
\hline 1 & $\mathrm{DDSQ}(\mathrm{Me})(\mathrm{OH})$ & $\operatorname{DDSQ}(i-\mathrm{bu})(\mathrm{H})$ & 72 & 100 & No reaction \\
\hline 2 & $\operatorname{DDSQ}(i-\mathrm{bu})(\mathrm{OH})$ & DDSQ $(i$-bu)H & 72 & 100 & No reaction \\
\hline 3 & $\mathrm{DDSQ}(\mathrm{Me}) \mathrm{H}$ & $\mathrm{DDSQ}(\mathrm{Me})(\mathrm{OH})$ & 12 & 90 & $\mathrm{P} 1$ \\
\hline 4 & DDSQ(Me)H & $\operatorname{DDSQ}(i-\mathrm{bu})(\mathrm{OH})$ & 12 & 90 & $\mathrm{P} 2$ \\
\hline
\end{tabular}

Reactions were seemed to be prevented due to the strong steric hindrance of $i$-Bu group at $\mathrm{SiH}$ site for the accommodation of $\mathrm{B}\left(\mathrm{C}_{6} \mathrm{~F}_{5}\right)_{3}$ catalyst at the end functional DDSQ units in run 1 and run 2 whereas, run 3 and run 4 allowed the progress of reactions, probably due to the relatively less steric hindrance of methyl group at $\mathrm{SiH}$ site as shown in Table 1. Polymer P1 and P2 were obtained according to scheme 3 with the recipes described in run 3 and run 4 in Table 1.

Tris(pentafluorophenyl)borane $\mathrm{B}\left(\mathrm{C}_{6} \mathrm{~F}_{5}\right)_{3}$ has been used in a number of organic and polymerization reactions, such as silylation of alcohol, hydrosilylation of carbonyls and thiocarbonyls at room temperature as a catalyst [24-27]. In this study, we used $\mathrm{B}\left(\mathrm{C}_{6} \mathrm{~F}_{5}\right)_{3}$ for the polycondensation of hydroxy end functional double-decker silsesquioxane and hydrogen end functional double-decker silsesquioxane. Although room temperature is sufficient to activate $\mathrm{B}\left(\mathrm{C}_{6} \mathrm{~F}_{5}\right)_{3}$ catalyst for the cross-dehydrocoupling reaction, we used relatively high temperature $\left(90-100^{\circ} \mathrm{C}\right)$ for the better dissolution of the monomers as well as the polymer formed during polymerization. The progress of polymeric reaction was confirmed by the vigorous bubbling of hydrogen by the dehydrocoupling reactions. Although we succeeded in the synthesis of new polymers from double-decker monomers, the molecular weights are rather low, and the polydispersity was rather high. The reason may be in the purity of the monomers. Further efforts to purify the monomers should be made. 


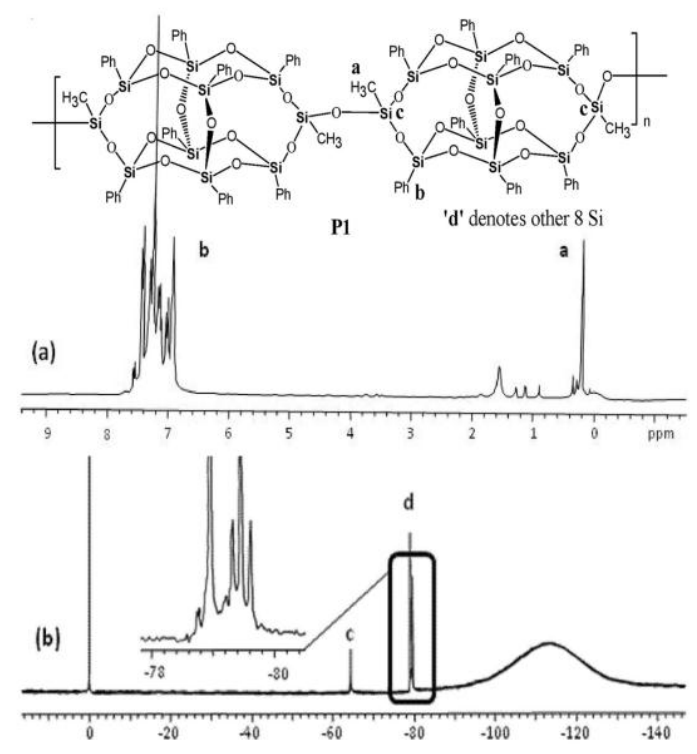

Fig. 1. (a) ${ }^{1} \mathrm{H}$ NMR and (b) ${ }^{29} \mathrm{Si}$ NMR of polymer P1.

In the ${ }^{1} \mathrm{H}$ NMR spectrum of P1 in Fig. 1 (a), the concomitant disappearance of $\mathrm{SiH}$ at $\delta=4.98 \mathrm{ppm}$ of DDSQ(Me)H with hydroxyl hydrogen $(\mathrm{Si}-\mathrm{OH})$ of the DDSQ $(\mathrm{Me})(\mathrm{OH})$ at $\delta=2.66 \mathrm{ppm}$ confirms the formation of polycondensation product. On the contrary, the appearance of protons chemical shifts of $\mathrm{SiCH}_{3}$ at new position, $\delta=0.21(\mathrm{~s}, 6 \mathrm{H})$ and $\mathrm{SiPh}$ at $\delta=6.91-7.50(\mathrm{~m}, 40 \mathrm{H})$ also support the formation of P1 polymer. The ${ }^{29} \mathrm{Si}$ NMR of P1 (Fig. 1b) reveals the disappearance of $\mathrm{Si}(\mathrm{Me}) \mathrm{H}$ signal at $\delta=-32.77 \mathrm{ppm}$ [of $\operatorname{DDSQ}(\mathrm{Me}) \mathrm{H}]$ and $\mathrm{Si}(\mathrm{Me})(\mathrm{OH})$ signal at $\delta=-53.91 \mathrm{ppm}[\mathrm{of} \operatorname{DDSQ}(\mathrm{Me})(\mathrm{OH})]$ and appearance of single new signal at $\delta=-64.44 \mathrm{ppm}$ of Si-O-Si bond connecting the DDSQDDSQ units strongly supports the formation of polymer P1. The signals of other eight Si atoms are appeared similarly as seen in the double decker monomers.

Fig. 2 (a) and (b) shows the ${ }^{1} \mathrm{H}$ NMR and ${ }^{29} \mathrm{Si}$ NMR spectrum of polymer P2. Similar to the $\mathrm{P} 1$, the ${ }^{1} \mathrm{H}$ NMR spectrum of $\mathrm{P} 2$ shows the concomitant disappearance of $\mathrm{SiH}$ at $\delta=$ $4.98 \mathrm{ppm}$ of DDSQ(Me)H monomer with hydroxyl hydrogen ( $\mathrm{Si}-\mathrm{OH})$ of the DDSQ $(i-$ $\mathrm{Bu})(\mathrm{OH})$ at $\delta=2.59 \mathrm{ppm}$ confirms the formation of polycondensation product. On the contrary, the appearance of protons chemical shifts of $\mathrm{SiCH}_{3}$ at new position, $\delta=0.08$ $(\mathrm{s}, 6 \mathrm{H})$ of DDSQ(Me)H unit and iso-butyl group chemical shifts at $\delta=0.22(4 \mathrm{H}), 0.63$ $(12 \mathrm{H})$ and $1.75(2 \mathrm{H}) \mathrm{ppm}$ assignable to $\mathrm{CH}_{2}, \mathrm{CH}_{3}$, and $\mathrm{CH}$, respectively, confirm the presence of both $\operatorname{DDSQ}(\mathrm{Me}) \mathrm{H}$ and $\operatorname{DDSQ}(i-\mathrm{Bu})(\mathrm{OH})$ in the polymer backbone. Again, the phenyl chemical shifts of SiPh are also present at $\delta=6.90-7.44(\mathrm{~m}, 80 \mathrm{H}) \mathrm{ppm}$ in the spectrum of polymer P2. The ${ }^{29} \mathrm{Si}$ NMR of P2 (Fig. 2b) reveals the disappearance of $\mathrm{Si}(\mathrm{Me}) \mathrm{H}$ signal at $\delta=-32.77 \mathrm{ppm}$ and $\mathrm{Si}(i-\mathrm{Bu})(\mathrm{OH})$ signal at $\delta=-55.95 \mathrm{ppm}$ of DDSQ(Me)H and DDSQ $(i-\mathrm{Bu})(\mathrm{OH})$, respectively confirms the polycondensation reaction product. At the same time the appearance of new signals at -64.97 and $-66.73 \mathrm{ppm}$ 
assignable to end capped $\mathrm{Si}(\mathrm{Me})$ and $\mathrm{Si}(i-\mathrm{Bu})$ proves the connection of DDSQ(Me)$\operatorname{DDSQ}(-\mathrm{Bu})$ giving polymer P2. The signals for other sixteen $\mathrm{Si}$ atoms are appeared similarly as seen in the double-decker monomers.

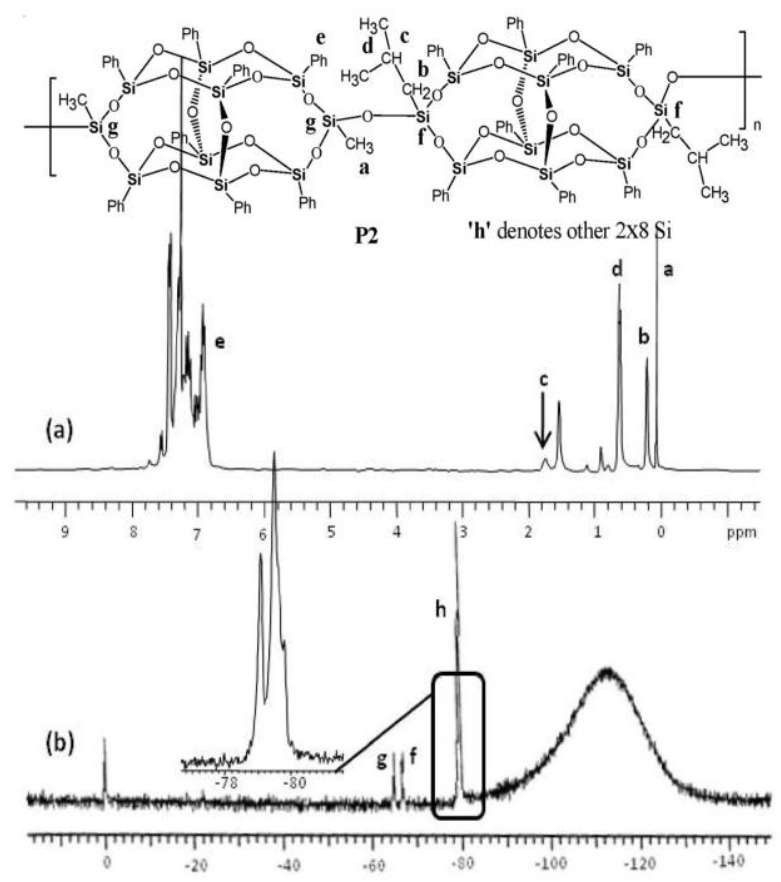

Fig. 2. (a) ${ }^{1} \mathrm{H}$ NMR and (b) ${ }^{29} \mathrm{Si}$ NMR of polymer P2.

\subsection{Thermal properties}

Thermal properties of polymers P1 and P2 were studied by thermogravimetric analysis (TGA) method and the thermal stabilities are shown as graphical representation in Fig. 3. From Fig. 3, it is seen that both the polymers exhibit good thermal stability in the range of $470-530^{\circ} \mathrm{C}$. The high thermal stabilities of these polymers arise due to the presence of double-decker silsesquioxane (DDSQ) unit in the main chain and phenyl substituent in the silsesquioxane structure [28]. Comparatively low thermal stabilities of both the P1 and P2 polymers in air are due to the early oxidative degradation of methyl and isobutyl substituent in the side chain at elevated temperature. It can be seen that $5 \%$ weight loss temperature $\left(T_{d 5}\right)$ for the $\mathrm{P} 1$ and $\mathrm{P} 2$ are around $470^{\circ} \mathrm{C}$ and $530^{\circ} \mathrm{C}$, respectively in nitrogen atmosphere and that are $470^{\circ} \mathrm{C}$ and $510^{\circ} \mathrm{C}$ respectively, in air atmosphere. 


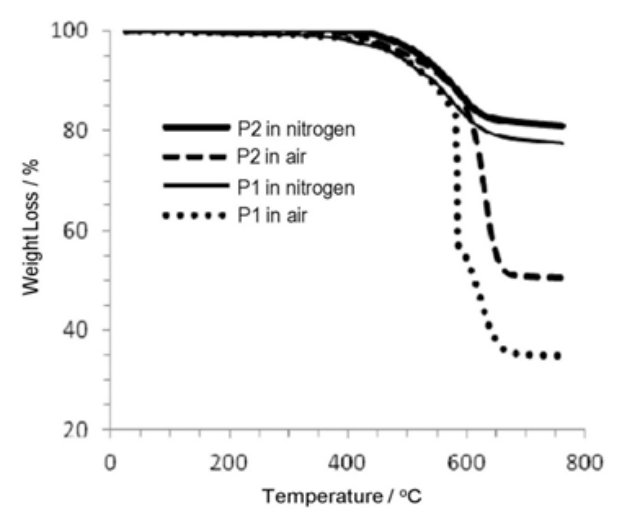

Fig. 3. TG analysis of $\mathrm{P} 1$ and $\mathrm{P} 2$ in nitrogen and air with the heating rate of $10^{\circ} \mathrm{C} / \mathrm{min}$.

The distinguishable low degradable temperature $\left(T_{d 5}\right)$ for $\mathrm{P} 1\left(470^{\circ} \mathrm{C}\right)$ compare to that of $\mathrm{P} 2\left(530-510^{\circ} \mathrm{C}\right)$ is assumed for the low packing density which arise from the isomeric irregular conformation of DDSQ(Me)-DDSQ(Me) unit in the polymer backbone. The residual weights for $\mathrm{P} 1$ and $\mathrm{P} 2$ are $78 \%$ and $81 \%$ in nitrogen and $36 \%$ and $51 \%$ in air, respectively. The high residual weight in nitrogen atmosphere suggests that P1 and P2 merely lost organic moieties from the backbone persisting siloxane/silsesquioxane backbone or slightly cleavage of backbone at $760^{\circ} \mathrm{C}$, whereas, in air atmosphere, the polymers were completely oxidized (form $\mathrm{SiO}_{2}$ ) with the complete cleavage of the backbone at $760^{\circ} \mathrm{C}[21]$.

\section{Conclusions}

Polymers with highly thermal stabilities were synthesized with the alternating incorporation of two different double-decker silsesquioxane units, (DDSQ)(Me)H and $(\mathrm{DDSQ})(\mathrm{Me})(\mathrm{OH})$, or $(\mathrm{DDSQ})(\mathrm{Me}) \mathrm{H}$ and $\operatorname{DDSQ}(i-\mathrm{Bu})(\mathrm{OH})$ in the backbone. Characterization with ${ }^{1} \mathrm{H}$ NMR, ${ }^{29} \mathrm{Si}$ NMR and SEC proved the formation of polysilsesquioxane. High thermal stability of DDSQ units resulted exceptional thermal stability of polysilsesquioxane up to $500{ }^{\circ} \mathrm{C}$ with no weight loss. Poor solubility as well as process ability of polysilsesquioxane containing methyl functional end capped doubledecker silsesquioxane poly(DDSQ(Me)) was improved by replacing methyl group with iso-butyl group as $\operatorname{DDSQ}(i$-Bu). Good process-ability, high thermal stabilities and chemical inertness of siloxane bond of these polymers would expand their applications to the adverse atmospheres.

\section{References}

1. J. M. Ziegler and F. W. Gordon, Eds., J. Am. Chem. Soc. 224, 47 (1990).

2. M. A. Brook, Silicon in Organic, Organometallic, and Polymer Chemistry (John Wiley and Sons, Inc., New York, 2000). 
3. Y. Kawakami, Y. Kakihana, A. Miyazato, S. Tateyama, and M. A. Hoque, Adv. Polym. Sci. 235, 185 (2011). http://dx.doi.org/10.1007/12 2010 55

4. M. Lewin, S. M. Atlas, and E. M. Pearce, Flame Retardant Polymeric Materials (Plenum Press, New York 1975). http://dx.doi.org/10.1002/pol.1976.130140912

5. P. R. Dvorinc and R. W.Lenz, High temperature siloxane elastomers, (Huthig \& Wepf, Basel 1990).

6. J. M. Zeigler, and G. F. W. Fearon, Eds., Silicon-based Polymer Science: A Comprehensive Resource (American Chemical Society, Washington, DC 1990). http://dx.doi.org/10.1021/ba$\underline{1990-0224}$

7. Y. Otomo, Y. Nagase, and N. Nemoto, Polymer 46, 9714 (2005). http://dx.doi.org/10.1016/j.polymer.2005.08.063

8. I. Sato, S. Takeda, Y. Arai, H. Miwa, Y. Nagase, and N. Nemoto, Polym. Bull. 59, 607 (2007). http://dx.doi.org/10.1007/s00289-007-0804-7

9. H. Ito, E. Akiyama, Y. Nagase, A. Yamamoto, and S. Fukui, Polym J. 38, 109 (2006). http://dx.doi.org/10.1295/polymj.38.109

10. S. Devaraju, M. R. Vengatesan, and M. Alagar, High Perform. Polym. 23, 99 (2011). http://dx.doi.org/10.1177/0954008310391825

11. L. Chyi-Ming, G. R. Mahesh, W. Kung-Hwa, and S. Ching-Fong, Chem. Mater. 15, 2261 (2003). http://dx.doi.org/10.1021/cm0208408

12. J. D. Lichtenhan, N. Q. Vu, J. A. Carter, J. W. Gilman, and F. J. Feher, Macromolecules 26, 2141 (1993). http://dx.doi.org/10.1021/ma00060a053

13. M. E. Wright, D. A. Schorzman, F. J. Reher, and R. Z. Jin, Chem. Mater. 15, 264 (2003). http://dx.doi.org/10.1021/cm020238h

14. T. S. Haddad and J. D. Lichtenhan, J. Inorg. Organomet. Polym. 5, 237 (1995). http://dx.doi.org/10.1021/ma960609d

15. Y. Lee, J. Huang, S. Kuo, J. Lu, and F. Chang, Polymer 46, 173 (2005). http://dx.doi.org/10.1016/j.polymer.2004.10.003

16. R. Tamaki, J. Choi, and R. M. Laine, Chem. Mater. 15, 793 (2003). http://dx.doi.org/10.1021/cm020797o

17. D. Neumann, M. Fisher, L. Tran, and J. G. Matisons, J. Am. Chem. Soc. 124, 13998 (2002). http://dx.doi.org/10.1021/ja0275921

18. J. Choi, J. Harcup, A. F. Yee, Q. Zhu, and R. M. Laine, J. Am. Chem. Soc. 123, 11420 (2001). http://dx.doi.org/10.1021/ja0107201

19. Z. Patrycja, D. Beata, K. Maciej, and M. Bogdan, Chem. Eur. J. 20, 9387 (2014). http://dx.doi.org/10.1002/chem.201402862

20. Z. Weihai, X. Jiuduo, L. Xuesong, S. Guanghe, and M. Jianxin, J. Polym. Sci., Part A: Polym. Chem. 52, 780 (2014). http://dx.doi.org/10.1002/pola.27058

21. M. A. Hoque, Y. Kakihana, S. Shinke, and Y. Kawakami, Macromolecule 42, 3309 (2009). http://dx.doi.org/10.1021/ma900124x

22. K. Yoshida, K. Ito, H. Oikawa, M. Yamahiro, Y. Morimoto, K. Ohguma, K. Watanabe, and N. Ootake, United States Patent Application 20040068074 (2004).

23. K. Yoshida, K. Ito, H. Oikawa, M. Yamahiro, Y. Morimoto, K. Ohguma, K. Watanabe, and N. Ootake, United States Patent Application 20040249103A1 (2004).

24. W. E. Piers, Adv. Organomet. Chem. 52, 1 (2004). http://dx.doi.org/10.1016/S0065-3055(04)52001-4

25. J. M. Blackwell, K. L. Foster, V. H. Beck, and W. E. Piers, J. Org. Chem. 64, 4887 (1999). http://dx.doi.org/10.1021/jo9903003

26. D. J. Parks and W. E. Piers, J. Am. Chem. Soc. 118, 9440 (1996). http://dx.doi.org/10.1021/ja961536g

27. D. J. Harrison, R. McDonald, and L. Rosenberg, Organometallics 24, 1398 (2005). http://dx.doi.org/10.1021/om048993n

28. H. Endo, N. Takeda, and M. Unno, Organometallics 33, 4148 (2014). http://dx.doi.org/10.1021/om500010y 